\title{
Oralidad, música y letras: la revolución de la palabra en la poesía de José María Arguedas y Candelario Obeso ${ }^{1}$
}

\author{
Andrea Angel Baquero \\ Magíster en Literatura \\ Western University \\ https://orcid.org/0000-0002-8765-5610 \\ aangel3@uwo.ca
}

\section{Resumen}

La poesía de Candelario Obeso (1849-1884) y José María Arguedas (1911-1969) rescata la expresión oral de las comunidades afrodescendientes y amerindias del río Magdalena en Colombia y de los quechua hablantes de Perú. La obra de ambos autores guarda una estrecha relación con la expresión oral de los pueblos y la musicalidad que emerge de la palabra en cantos y festejos tradicionales. Este artículo analiza la obra poética de estos dos autores en su propósito por recuperar las voces marginadas en los proyectos de conformación de la Nación. Su escritura reivindica la riqueza poética de las formas de expresión cotidiana de estas comunidades.

Palabras clave: afrodescendiente; amerindio; expresión oral; poesía; Quechua.

\section{Orality, music, and letters: the revolution of the word in the poetry of Jose Maria Arguedas and Candelario Obeso}

\section{Abstract}

The poetry of Candelario Obeso (1849-1884) and José María Arguedas (1911- 1969) rescues the vernacular of the afro-descendants and indigenous communities of the Magdalena River in Colombia and Quechua speakers of Peru, respectively. The work of both authors is closely related to the oral expression of the peoples and the musicality that emerges from the word in traditional songs and celebrations. This article analyzes the poetic work of these two

\footnotetext{
${ }^{1}$ Procedencia del artículo: Este artículo hace parte de un trabajo de investigación doctoral sobre la obra de Candelario Obeso y José María Arguedas.
}

Esta obra está bajo una Licencia Creative Commons Atribución-NoComercial Compartirlgual 4.0 Internacional. 
authors in their purpose of recovering marginalized voices in nation-building projects. Their writing claims the poetic richness of the forms of everyday expression of these communities.

Keywords: afro-descendant; indigenous people; oral expression; poetry; Quechua.

Recibido: 23 de enero del 2021. Aprobado: 05 de marzo del 2021

Artículo de reflexión https://doi.org/10.25100/poligramas.v0i52.11337

\begin{abstract}
¿Cómo citar este artículo en MLA? - How to quote this article in MLA?
Angel Baquero, Andrea. "Oralidad, música y letras: la revolución de la palabra en la poesía de José María Arguedas y Candelario Obeso" Poligramas 52 (2021): e.2411337. Web. Fecha de acceso (día, mes en mayúscula y abreviado, y año).
\end{abstract}

Si pensáramos en una suerte de génesis de la palabra, del momento mismo cuando la capacidad del hombre por emitir un sonido que fuera entendido por otro sucediera en un espacio y tiempo determinados; habría que pensar que en ese principio la palabra y la música se encontraron, como sugiere Lawrence Kramer. La música representa la figura o voz de la divinidad y el lenguaje es simbolizado abordando lo inefable (2). En un principio fue el canto, hasta que se separó música y poesía para que ambas tendieran a volverse nostálgicas, cada una por la ausencia de la otra (3). Ese origen, que para este autor es conjunto y no deja de mantener estrechas relaciones, incluso en el presente, tuvo también su inicio en las comunidades originarias que se encontraron en América para el momento de la Conquista. La estrecha relación entre poesía y música mantuvo sus lazos en la tradición oral, los cantos y la palabra de los afrodescendientes e indígenas. Candelario Obeso en Colombia y José María Arguedas en Perú buscaron rescatar en su poesía los vestigios musicales de la palabra o la poesía musical del canto.

Este trabajo relaciona la obra poética de estos autores y el propósito que encierra, debido a que ambos partieron de la necesidad de darle un lugar a los excluidos dentro de los márgenes de la Nación. Para ello, primero se analiza la poesía de cada uno en su íntima relación con la 
oralidad de las culturas ancestrales. Segundo, se subraya la importancia del rescate de la lengua como un medio de resistencia ante la lengua castiza impuesta. Por último, se resalta cada una de las propuestas literarias de los autores como un intento por derrumbar los muros que históricamente mantuvieron marginadas a estas poblaciones. Es este un acercamiento al lirismo que se esconde en la palabra y a la fuerza de la lengua como baúl del pensamiento y la cultura.

\section{En las profundidades del problema}

Durante el periodo de la colonización, los españoles necesitaban imponer sus prácticas culturales a toda la población, incluyendo a los esclavos y los indígenas. Para tal fin, demonizaron las prácticas religiosas y culturales de todos los grupos sociales, reduciéndolas a canibalismo y brujería. De acuerdo con Jaime Humberto Borja, el concepto occidental del mal y el demonio son una construcción histórica consolidada por el cristianismo europeo (21). Con la llegada de los españoles a América, la satanización de lo no conocido fue configurándose paulatinamente. De esta manera, se llevó a cabo una ocupación territorial, espiritual y cultural que tuvo como principio la Conquista y se prolongó en el tiempo.

Como plantea Borja, de acuerdo con la tradición según la cual se identificaba al "otro" con lo bárbaro y se tildaba como pagano todo lo que se escapaba de la comprensión de la realidad, tras su llegada a América, los españoles empezaron a ver al mal y lo que este representaba en todo lo que encontraban a su paso (47). Los cultos, las costumbres y los comportamientos de los indígenas sirvieron como muestra contundente de que Satanás se había hospedado en las tierras inhóspitas que ellos apenas conocían. Con el paso del tiempo y ante la acelerada mortandad de la población indígena, se empezó a recurrir a la mano de obra de los negros, traídos como esclavos desde África, para abrir caminos que permitieran a los españoles conquistar la totalidad del territorio. A su vez, los esclavos fueron usados para la minería, el servicio doméstico, e incluso, para el enfrentamiento con algunos grupos indígenas.

Los colonizadores estaban convencidos de que la cristianización del indígena desterraría lentamente al demonio, sin embargo, la imagen satanizada del "otro", pronto se consolidó sobre el negro. Esta idea se afianzó debido a la fuerte resistencia de los esclavos por el trabajo forzado, la cristianización y las costumbres blancas (104). Así, a la población afro, en una actitud similar a la que se tomó frente al indio, se le excluyó y rotuló debido a las diferencias culturales y prácticas que la caracterizaban. Fue en el encuentro entre europeos, africanos e 
indígenas, reunidos en un mismo espacio geográfico, que los españoles recurrieron a la evangelización para imponer sus normas culturales provenientes de Europa y sus principios occidentales, medio por el cual se pretendió borrar todo rastro cultural alejado de la cosmovisión impuesta.

Tiempo después y como sugiere Benedict Anderson en su libro Comunidades imaginadas, el desarrollo de la imprenta y el establecimiento de una lengua nacional, originó la conciencia nacional. Este proceso se dio, primero, porque la impresión de libros en lenguas vernaculares dio lugar a campos unificados de intercambio y comunicación, que paulatinamente sentaron las bases de las naciones como comunidades imaginadas. Segundo, debido a que el capitalismo impreso ayudó a construir la imagen de antigüedad de la lengua, central en la subjetiva idea de Nación. El capitalismo impreso creó las lenguas de poder (44-45). En ese sentido, como explica Carlos Jáuregui, los peninsulares que pretendían ejercer un dominio sobre los territorios recién "descubiertos" y sobre los pobladores que en ellos habitaban, impusieron su lengua como una herramienta de control. Estas lógicas crearon las bases, que con el paso del tiempo, fueron penetrando las creencias, las formas de vida y los mecanismos para comprender la realidad (45-46). En los posteriores procesos de conformación de las naciones latinoamericanas, el purismo de la lengua se mantuvo en el imaginario como símbolo de civilización y superioridad racial. Además, se le atribuía una idea de comunión a las naciones recientemente conformadas y construidas, bajo la noción de una afinidad con el otro en términos de territorio, lengua e historia.

\section{Navegando en un río de notas, poesía y música}

Para este análisis se tuvo en cuenta el poemario de Obeso Cantos populares de mi tierra, algunos poemas de Arguedas y las canciones traducidas del quechua por él. Hacen parte del análisis estas últimas debido a que, como el mismo autor explica, muchas de las canciones fueron modificadas por su propia mano para que tuvieran mayor fuerza expresiva y poética, por lo cual, si bien es un intento por mantener viva la cultura, es también una obra de creación personal.

A finales del siglo XIX en Colombia, la literatura del país buscaba reafirmar la identidad nacional. Candelario Obeso nació en 1849, tres años antes de que se aboliera la esclavitud. Mompox, su lugar de origen, estaba ubicado al lado del río Magdalena, este era un lugar 
fundamental en la época para el transporte fluvial de diferentes elementos. Por su corriente podían ser transportados todos los encargos (libros, joyas, pianos, ropa, etc.) dirigidos a la capital (Bogotá), ubicada en el centro del país, que para ese entonces era un lugar inaccesible por tierra. Debido a las demandas comerciales, culturales y de transporte que requería la capital, el Magdalena se convirtió en el principal medio de comunicación entre la costa y el centro. Por el río se movían la cultura y los viajeros, transportados por los remos de los bogas (remeros de los transportes fluviales del siglo XIX, generalmente afros y en algunos casos, indígenas).

Obeso creció en un contexto atípico por su condición de negro. Su colegio fue uno de los primeros en aceptar estudiantes descendientes de esclavos. Posteriormente, Obeso se fue a la capital a estudiar en la Universidad Nacional, y aunque no se graduó por razones económicas, obtuvo el diploma de maestro. Dentro de su obra están algunas traducciones de textos literarios y militares, cursos de francés e inglés, una obra teatral y un poemario, entre otras. La poesía de Obeso relata las vivencias de los bogas y otros habitantes (campesinos, montaraces, pescadores e indígenas), desde las particularidades de su lengua vernácula aunada a una profunda sensibilidad relacionada con el ritmo del remo y la cadencia de los compases musicales con que estos habitantes entretenían al viajero o se distraían en la faena.

Arguedas nació en Perú a principios del siglo XX, su vida estuvo marcada por una dualidad identitaria; su padre hacía parte de la cultura letrada y acomodada, sin embargo, debido a las largas ausencias por su trabajo como abogado litigante, Arguedas, que era despreciado por su madrastra, fue conminado a vivir con los indios. Estos lo acogieron y aprendió a hablar y sentir el quechua como su lengua materna, razón por la cual, creció hablando esta lengua y conoció de cerca la cosmovisión andina. Su poesía y las canciones quechuas recuperadas y recopiladas por él, resaltaban la fuerza poética en las formas de expresión indígena. Sus poemas y canciones, escritos en la lengua de sus ancestros, pretendían también resaltar la sonoridad característica de esta y la cultura oral de sus hablantes.

En el ensayo introductorio al libro Canto Kechwa, Arguedas sostiene que la poesía nació con el imperio Inca y que esta está profundamente arraigada al mito (Rebaza 87). Para el poeta, la poesía no solo provenía de la cultura de sus antepasados, sino que reconocía que, en sus bailes, su música y sus fiestas existía toda una suerte de acompañamiento a la palabra convertida en poesía (Arguedas, Canto Kechwa 10). De acuerdo con Kramer, música y poesía son artes que comparten su tangible organización del flujo del tiempo (4). Intratextualmente, 
hay un diseño rítmico, un tipo de temporalidad en la cual la experiencia del paso del tiempo se concreta y percibe enriquecida entre un principio y un final definido (8). Esta comunión entre el ritmo poético y el compás musical se hace evidente en los poemas de Arguedas y Obeso, no solo porque hay una métrica que rige los versos, sino porque desde su composición, es decir, desde la lengua que los evoca, hay ya un acorde armónico que tiene su origen en la oralidad.

La relación entre música y poesía no era insólita para el momento en que Obeso y Arguedas escribieron sus poemas y cantos. La poesía occidental nació ligada a la música. Canto, melodía y lenguaje estaban entrelazados por los ritmos de la respiración convertida en voz. La voz funcionaba musicalmente en la realización y transmisión de todo discurso poético cuando la producción y transmisión del arte verbal eran producidas exclusiva y predominantemente por vía audio-oral. La poesía antigua medieval fue en su mayoría cantada o entonada. Lo mismo sucedió con la épica de los griegos, los romances de la tragedia antigua y el teatro medieval (Neiva de Matos 83-84).

Solo con el fin de la Edad Media, en donde se dio la difusión de la cultura escrita, el Clasicismo, el progreso de la instrumentalización y la notación musical; la palabra poética y la sonoridad rítmico-melódica desligaron los vínculos que las unían. Así, se desarrolló la música instrumental, producida plenamente para la audición, y la poesía escrita, hecha para ser leída en silencio y ser apenas cantada en la mente del lector. Lo que más interesaba a los viejos teóricos y comentadores de la llamada Poética Clásica de la Antigüedad y el Renacimiento en el siglo XVIII francés, era su capacidad de recrear seres y acciones para la imaginación sensorial de quien escuchaba (84). Las afinidades entre poesía y música fueron posteriormente exploradas por pre-románticos y románticos, principalmente en la filosofía y los estudios literarios (86). En los últimos cien años, el interés por el sustrato musical de la poesía y por la asociación de la música en las obras de palabra cantada, se desarrolló en diferentes áreas y vertientes transdisciplinares, como los estudios folclóricos, la etnomusicología y la etnopoética (91).

Como explica Nelson Osorio, las lenguas indígenas en América — y yo agregaría la lengua vernácula de las comunidades afros_-, son parte de una cultura de la oralidad. Así, lo que Occidente llama poesía, para los pueblos originarios es sentimiento que se formaliza en palabra, música y danza (572). En el antiguo imperio de los Incas, señala Ángel Rama, la música y la poesía formaban un mismo universo. En la poesía, la palabra brota junto a la música (24-25). 
Lo anterior, podemos verlo, primero, en uno de los poemas más representativos de Obeso que desde su título hace una alusión musical Canción del boga ausente: "Que trite que etá la noche/ la noche que trite etá/ no hai en er cielo una etrella.../ remá, remá" (Obeso 66). Como bien destaca Jáuregui, el poema se refugia en el ritmo de los dos golpes de remo, de ahí proviene el remá remá, que luego es bogá bogá y finalmente llorá Ilorá (Entre la espada 572). En cuanto a Arguedas, sus poemas en quechua, igual que las canciones, mantienen un ritmo propio de la lengua, que a pesar de la incomprensión del significado se aprecia en la composición, tal y como puede percibirse en el siguiente fragmento de Katatay: "Llactay puyus katatachkan/ warmikunapa llaki puyu sonqonwan tupaykuspa/ ¡Ama katataychu, llaki,/ kunturpa sombranmi hamuykuchkan!" (Arguedas, Katatay 44). Asimismo, en uno de sus ensayos, Arguedas recrea un episodio de su vida en el que presenció a un grupo de mujeres indígenas que cantaban en grupo mientras los hombres molían con los pies la vaina seca de las alverjas al compás del ritmo. En este caso, la música acompañaba el trabajo de los indígenas en la trilla de la alverja (Rama 23).

La experiencia musical que subyace de la lectura de los poemas de Obeso y Arguedas subraya el planteamiento de Kramer respecto al hecho de que la música tiene el poder de encarnar complejos estados de la mente, tal y como ellos surgen de manera pre verbal en la conciencia. Quizás, por este hecho, la experiencia que emana tras la lectura de estos poemas es, como describe este autor; una experiencia anterior a la palabra, aunque esté precedida por ella (7). A su vez, esta sonoridad poética tiene como origen la composición onomatopéyica de los versos. En ese orden de ideas, los grafemas hacen referencia directa a los fonemas que parecen brotar de la lectura con toda su musicalidad. En su ensayo sobre el origen de las lenguas Rousseau expresa lo siguiente: "Los versos, los cantos, la palabra tienen un origen común (...) los retornos periódicos y acompasados del ritmo, las inflexiones melodiosas de los acentos hicieron nacer, con la lengua, a la poesía y a la música" (Neiva de Matos 86). En su análisis de la obra arguediana, Rama plantea cómo en su escritura la palabra es vista como sonido. En un momento histórico en el que la poesía ya se había tornado escritura, Arguedas la seguía percibiendo como fonema (24).

Mi propuesta es que, tanto Obeso como Arguedas buscaron enaltecer la profunda relación entre poesía, música, voz y canto, presente en la cotidianidad de las comunidades ribereñas colombianas e indígenas peruanas, a través de su obra poética. Así como en el origen de la 
poesía occidental, pensada para ser cantada o entonada, estas comunidades con hablantes en su mayoría ágrafos empleaban sus cantos, su poesía y su música para el mismo fin. Los poemas evidencian un esfuerzo por recrear espacios y acciones para la imaginación sensorial de sus lectores. De los versos emergen los sonidos de las campanas, las cascadas, el río, los remos, el llanto, entre otros. Todos estos elementos hacen parte de la composición musical, recrean la vida cotidiana y se inscriben dentro de los múltiples recursos sonoros que conforman la presencia de una orquesta, como alude metafóricamente Rama (27).

En los poemas de Obeso, surgen los ritmos de los bailes "Caliente taba er baile;/ yo retraío,/ lleno e la timirece/ re un barba- limpio" (Obeso 80), el silencio de la noche "Qué ejcura que etá la noche;/ la noche que ejcura tá;/ asina ejcura e la ausencia/ bogá bogá!" (68), el fluir del río "Amo yo la libectá/ como er pájaro a su nío;/ como la flore a la lluvia,/ como ar agua er bocachico" (100), entre otros. Los espacios escogidos por el autor para dar lugar a sus versos eran los mismos lugares donde indios, pescadores, bogas y montaraces vivían, en su mayoría, parajes apartados de las ciudades en donde desempeñaban su trabajo, rodeados de la naturaleza. Lo anterior puede verse en el siguiente poema, en donde se relaciona la luna y la noche con el momento en que el pescador ejerce su labor: "Ahí viene la luna, ahí viene/ con su lumbre y clarirá/ ella viene i yo me voi/ a pejcá" (Obeso 128).

En el caso de Arguedas, los sonidos extraídos de la naturaleza cobran un gran valor en la medida en que se usan como metáfora de aquello que el autor busca dar a entender. En el prólogo de Canto Kechwa, el poeta explica cómo cuando se encontraba en reuniones con otros indígenas, todos oían el ruido de la cascada y lo asimilaban con un instrumento o parte de la composición musical del momento. A su vez, explica cómo se asociaba la voz de una mujer con el silbido del viento (Arguedas 10-11). En el poema A nuestro padre creador Túpac Amaru, puede verse la relación de los elementos de la naturaleza, la danza y el ruido-canto producido por elementos circundantes, con la unión de los pueblos indígenas: "Del movimiento de los ríos y las piedras, de la danza de árboles y montañas, de su movimiento bebemos sangre poderosa, cada vez más fuerte. ¡Nos estamos levantando, por tu casa, recordando tu nombre y tu muerte!” (Katatay 17). En ese orden de ideas, las evocaciones de los poemas mantienen vínculos con la sonoridad musical de los elementos a los que aluden. De los cantos en quechua también emergen el sonido del río "ya ves como lloro,/ gritando/ como el río, como el viento" (Arguedas, cuentos y cantos quechua 37), el soplo del viento "Cuando sopla el viento el ishu se agacha" 
(45) y el cantar de los pájaros "En los cerros fríos canta el pukupukul hace su nido entre las pajas" (Arguedas, Cantos y cuentos quechuas 53).

En suma, como sugiere Regina Harrison, Arguedas buscaba resaltar el poder onomatopéyico del quechua en su poesía (125) y recrear en los cantos el sonido de los elementos a los que alude. Obeso, por su parte, retomó los cantos melancólicos de los marginados, empleados para apaciguar sus arduas faenas como parte de la riqueza oral de los pueblos ribereños (Ortiz y Valdelamar 15). De esta manera, ambos autores tienen como punto de partida la oralidad de las comunidades en las que se inspira su poesía, además de las múltiples confluencias en los temas que abordan. El amor, la soledad, la vida errante y la tendencia a increpar al otro para buscar un espacio más justo dentro de la Nación son parte del entramado bajo el cual no solo se busca recuperar la oralidad y resaltar la musicalidad de la palabra, sino también, retratar la vida del afro y del indígena desde el distanciamiento en el que se les ha mantenido por años.

\section{En los imbricados orígenes de la lengua}

Mauricio Ostria denomina como "oralidad ficticia" (72) a todas las formas de imitación de la oralidad en América Latina a través de textos literarios escritos. En esta categoría podría encajar la poesía de Arguedas y Obeso, en tanto que ambos establecen una conexión entre los cantos

y la musicalidad de las comunidades de origen con las expresiones y ritmos de sus versos. Asimismo, sus poemas recrean la particularidad lingüística de los hablantes; lengua quechua y vernácula, respectivamente.

Con sus poemas, Obeso rompió con la tradición de la literatura oficial de mostrar al boga como un personaje feliz, como sucede en María de Jorge Isaacs, texto canónico en Colombia. La representación de Obeso es más realista y solidaria con este sector de la población, al hacer explícitas sus preocupaciones y problemas (Palacios 159). Por lo tanto, en Cantos populares de mi tierra, como plantea Jáuregui, Obeso optó por un registro de la lengua vernácula popular de la región de Mompox, para así, además de afirmar el dialecto, aseverar su identidad afrohispana que interpelaba a la nación blanca de entonces (La literatura "afronacional" 48). Obeso pretende con sus poemas una doble traducción; la de la oralidad de los sectores marginados por la cultura y literatura dominante, así como una traducción de lo afro a lo 
nacional, en donde la lengua vernácula termina constituyendo materia legítima para la literatura nacional (54).

Como proyecto literario, en la sustitución del habla castiza por la lengua vernácula pudo haber un intento de parte de Obeso por sentar las bases de un nuevo género, como sugiere Ramiro Lagos, en donde se llevaría a cabo una fusión entre lo culto y lo popular (223). El poema más reconocido de Obeso Canción del boga ausente, está dedicado entre muchos otros, a Rufino José Cuervo y Miguel Antonio Caro. Estos dos personajes eran los dos gramáticos más importantes de Colombia, este rótulo estaba también asentado en el hecho de que ambos pertenecían a familias adineradas y que su condición de blancura les otorgaba un espacio privilegiado dentro de la ciudad letrada. La dedicación podría pensarse de varias maneras, no obstante, parecería un guiño del autor o un acto de rebeldía el que su poema más importante, el cual se oponía al casticismo tradicional del que Caro y Cuervo eran defensores acérrimos, estuviera directamente dirigido a ellos. En ese orden de ideas, podría decirse que el poemario estableció una ruptura en los anales de la literatura nacional.

Asimismo, según lo planteado por Jorge Palacios, podría pensarse que la poesía de Obeso podría ser catalogada como "literatura menor" (170). La literatura menor, según los planteamientos de Deleuze y Guatari, tiene tres características principales. Primero, que en ella la lengua está marcada con un alto coeficiente de desterritorialización. Segundo, que su naturaleza está ligada a lo político; y tercero, su valor enunciativo colectivo en donde el sujeto habla a través de una suerte de voz que representa a un grupo de personas. Estas tres características tienen como objetivo el generar una solidaridad capaz de apelar a la sensibilidad con miras a la creación de una conciencia (16-17). En consecuencia, la poesía de Obeso estaría configurada a partir de la desterritorialización de la literatura mayor y la lengua de poder por medio de un doble gesto: hablando políticamente al impugnar la exclusión de los marginados, e imponiendo una voz colectiva donde los afros podían pensarse más allá de las dinámicas socio-culturales del momento (Palacios 157).

En lo que respecta a Arguedas, su producción poética también podría pensarse bajo las características de la literatura menor. Primero, porque el quechua había sido marginado desde la Conquista, y tras años de imposición de los imaginarios culturales europeos, había sido rotulado y denigrado. Por esta razón en muchos colegios, como explicaba Arguedas, se prohibía el uso del quechua y se ridiculizaba a todo aquel que lo empleara. Segundo, porque sus cantos 
y poemas tienen un alto sentido político, en la medida en que buscan probar que las formas de expresión del indio son poéticas, y porque también invitaban a la conformación de una nueva identidad andina que dejara atrás la supresión del indio y más bien lo acogiera con su cultura y con su lengua. Por último, en los poemas del poeta peruano siempre hay un llamado a la colectividad y la organización, un llamado a la lucha o a la interpelación del otro que históricamente los ha ignorado o acallado: "Sabemos bien qué ha de suceder. Que camine la muerte hacia nosotros; que vengan esos hombres a quienes no conocemos. Los esperaremos en guardia, somos hijos del padre de todos los ríos" (Arguedas, Katatay 15).

La figura literaria de Arguedas se configura a partir del mestizaje que vincula a la lengua con la cultura ancestral. Su obra, en ese sentido, es producto y expresión del mundo andino (Osorio 75). Para Arguedas, lengua y cultura estaban sujetas, y es por esa razón que el problema de la depreciación de la cultura ancestral estaba íntimamente ligado con la lengua. Como explica Luis Rebaza, en su compromiso con el lenguaje, el peruano creó un estilo literario de alto nivel poético en el que configuró un nuevo ser nacional, para que así las fuerzas de un contexto occidental se dirigieran hacia lo andino (54-55). Es desde el lenguaje donde se articula el intercambio de prácticas culturales que, perteneciendo a repertorios distintos, pueden establecerse como equivalentes. Arguedas se percató de que el quechua es un idioma capaz de expresar los sentimientos más profundos que emanan del espíritu y de la cultura, puesto que es este, y solo este sistema lingüístico, el que contiene la expresividad de la palabra capaz de evocar las vivencias, cosmogonía y vejaciones de las que fueron víctimas las comunidades (Mamani 53).

El objetivo de los cantos y la poesía en lengua quechua es el de plantear un proyecto literario capaz de transmitir la amplia realidad del mundo andino. Por lo cual, además de escribir en quechua, su obra tuvo como fin el encontrar una forma de expresión para ese mundo, y para ello construyó una expresión literaria en castellano, para dar a conocer la cultura y realidad de sus hablantes. De lo contrario, toda la realidad a la que hace alusión la obra de este autor quedaría circunscrita únicamente a los quechua hablantes. 


\section{¿Un disparo a la nación?}

De acuerdo con Christopher Laferl, la Nación siempre se representa como un cuerpo homogéneo, sin embargo, esta representación abarcadora en realidad deja por fuera a muchos de sus miembros. Así, se acuden a definiciones universales en apariencia, pero que solo representan una parte del todo (46-47). En el caso de Obeso, la inclusión literaria de los dialectos de diferentes sectores de la población no significó ninguna novedad. En el Romanticismo, como se señaló anteriormente, ya se había retratado al negro y se había imitado su voz en contraste con el español castizo. De esta manera, se situaba la oralidad de estas comunidades en el espacio de la anomalía (Jáuregui, La literatura "afronacional"50). Colombia, se impuso como Nación a través de una serie de actos violentos más que por un acto de imaginación; lo cual, incluyó a la gramática como una de las violencias integradoras de esta (50-51). En contraste, Obeso retrató en su obra lo que ya el campo literario y la sociedad letrada concebían como su opuesto, es decir, el desorden e irregularidad de la oralidad perteneciente a los sectores étnicos al margen de la identidad nacional (52).

En la poesía del colombiano, los bogas, montaraces, pescadores y demás habitantes de las riberas del río Magdalena, ya no estaban representados como seres susceptibles de domesticación y a la espera de la mano civilizadora del blanco capaz de domeñar su estado salvaje. Por el contrario, en sus versos se humanizó a estas poblaciones y se les mostró bajo sus propios referentes culturales, con visiones y conceptos propios de la vida y de sí mismos (Ortiz y Valdelamar 25). En ese orden de ideas, Obeso rompió con la tradición de mostrar a los grupos étnicos excluidos del centro del poder como menores de edad, sus vidas no giraban en torno a la espera del letrado, sino que trascurrían a pesar de ellos y queriendo mantenerse en ese estado, como puede verse en el siguiente fragmento del poeta Canto der montara: "Eta vira solitaria/que aquí llevo,/ con mi jembra i con mi s`hijo/ i mi perros,/ no la cambio poc la vira/ re lo pueblos" (Obeso 74).

En la sociedad colonial, el prestigio que adquirió la letra escrita y la lengua castiza vino por asociación al imaginario instituido por los españoles años atrás en el periodo de la Conquista, cuando se impuso el español como la lengua civilizada y se le asoció con el poder. Este hecho trajo consigo que la lengua ceremonial, protocolaria y escrita, como sugiere Jáuregui, se opusiera al desorden de la lengua popular cotidiana de todas los grupos étnicos que durante años se habían sometido; primero a las imposiciones europeas, y luego a la invisibilización de 
los criollos que solo pretendían incluir en su modelo de Nación a la minoría blanca que habitaba las principales ciudades del país (La literatura "afronacional" 51).

Por lo tanto, el poemario de Obeso confrontó las fronteras imaginadas por las élites de la época y retrató a los habitantes del margen de la comunidad imaginada. En palabras de Lawrence Prescott: "Las acciones de Obeso podrían considerarse llantos de ira, frustración y lucha contra los muros de prejuicios e indiferencia a los cuales la sociedad parecía reacia a reconocer" (13). No obstante, su poemario también implicó una ambivalencia cultural debido a que representaba un intento de ser reconocido por parte de la élite letrada del país.

En el caso de Arguedas, su obra se dio en un momento en donde sucedió un desplazamiento histórico de lo que representaba el indio, para dar paso a la configuración del hombre andino. En ese sentido, la idea de Nación como unidad en lo futuro, pretendía unir lo español y lo indio. Los indígenas que habían sido mantenidos al margen, ahora se empezaban a contemplar como una parte necesaria para la construcción de la pluralidad cultural y étnica del Perú (Rebaza 43-44). La obra de Arguedas estuvo en medio de la discusión por la identidad nacional. En consecuencia, el proyecto de sociedad que su obra encarna, como plantea Alberto Escobar, es el de una suerte de tejido tramado a partir de la conjugación de diferentes matices que fluyen a través del multilingüismo (70). Este proyecto, estaba edificado en su constante angustia ante la posible desaparición del arte popular y es debido a esto que su obra es una interpelación al lector para que no desatienda y olvide las diferentes formas de narrativa y poesía quechua (85).

En el prólogo de Canto Kechwa, Arguedas narra el caso particular de unos indios que trabajaban para una especie de señor feudal, y que podría decirse le pertenecían a este. Ese grupo de indios trabajaban desde temprano en la mañana, y en la tarde cuando llegaban a los lugares en los que dormían, solo comían y se acostaban. Nadie sabía cantar, no llevaban a cabo ningún tipo de festejo o celebración conjunta. Al autor, esta realidad lo conmovía, era como si hubieran sido desprovistos de su esencia, y ese hecho diera paso a la animalización de la que eran víctimas. Ante esta situación, él mismo se cuestionaba: ¿por qué hay una vergüenza por asumir esos cantos y esa tradición oral como propia? Ante este problema de negación de las raíces en el Perú, Arguedas sugirió que el primer paso para solucionar esa marginalización histórica estaba en reconocer que los cantos son arte, música y poesía. Por lo cual, era preciso hacer énfasis en este hecho para que, finalmente, se asumiera que lo indígena no es inferior. 
En resumen, en su escritura hay una poética de la movilización, de la fluidez y de la vitalidad. Es como las aguas en movimiento debido a que su propuesta revela la idea de una reacomodación social con la consigna de la reivindicación (Mamani 51).

Es importante resaltar que las similitudes entre Obeso y Arguedas no se limitan solo a la musicalidad, la lengua y la necesidad de incluir a los marginados en los proyectos de Nación. Tanto Obeso como Arguedas pusieron fin a su vida por mano propia. Obeso se pegó un tiro en el estómago, tras tres días de agonía murió a sus 35 años. Arguedas, después de meditarlo y dejarlo consignado en sus cartas y en su diario, se disparó en la cabeza y después de cuatro días murió. ¿De qué manera nos interpelan estas muertes? Son sus suicidios, tal vez, un signo de la crisis del espacio literario y un intento, siempre truncado, por hacer una relectura de la historia desde la voz de los oprimidos (La literatura "afronacional"64). Estamos llamados todos a no enterrar sus obras, como se enterraron sus cuerpos con la conciencia de las promesas rotas de la Nación por incluir a todos sus habitantes. La obra de estos dos autores debe ser un recuerdo constante de la pluralidad, el multilingüismo y la riqueza cultural que pervive en Latinoamérica.

\section{Referencias}

Anderson, Benedict. Comunidades imaginadas: Reflexiones sobre el origen y la difusión del nacionalismo. Mexico D.F: Fondo de Cultura Económica, 1993. Impreso.

Arguedas, José María. Canto Kechwa. Lima: Editorial Horizonte, 1989. Impreso.

Arguedas, José María. Cantos y cuentos quechuas, Lima: Municipalidad de Lima Metropolitana, 1986. Impreso.

Arguedas, José María. Temblar Katatay. Lima: Instituto Nacional de Cultura, 1972. Impreso.

Borja, Jaime Humberto. Rostros y rastros del demonio en la nueva granada indios, negros, judíos, mujeres y otras huestes de Satanás. Bogotá: Ariel Historia, 1998. Impreso.

Deleuze, Guilles, and Guattari, Félix. Kafka: Toward a Minor Literature. Minneapolis: University of Minnesota Press, 1986. Impreso.

Escobar, Alberto. Arguedas o la utopía de la lengua. Lima: Instituto de estudios peruanos, 1984. Impreso.

Harrison, Regina. "José María Arguedas: sustrato quechua." Revista Iberoamericana. (1983): 111-132. Web. 
Jáuregui, Carlos. "Candelario Obeso: entre la espada del Romanticismo y la pared del proyecto nacional." Revista Iberoamericana. (1999): 567- 590. Web.

Jáuregui, Carlos. "Candelario Obeso, la literatura "afronacional" y los límites del espacio literario decimonónico." Chambacú la historia la escribes tú. Madrid: Iberoamericana. 2007: 4768. Impreso.

Kramer, Lawrence. Music and Poetry: The Nineteenth Century and After. Berkeley: University of California Press, 1984. Impreso.

Laferl, Christopher. "La homogeneización de la nación en la época de la independencia: Bolívar, Olmedo, Bello." Escribiendo la independencia: Perspectivas postcoloniales sobre la literatura hispanoamericana del siglo XIX. Madrid: Iberoamericana. 2010: 45-62. Impreso.

Lagos, Ramiro (1982) "La poesía ebanita y su precursor Candelario Obeso." Boletín cultural y bibliográfico. (1983): 217-227. Web.

Mamani, Mauro. "'El poderoso que habla': El río y las dinámicas en la poesía de José María Arguedas." Letras. (2011): 45- 63. Web.

Mattos Neiva de, Cláudia. "Poesia e Música: laços de parentesco e parceria." Palabra cantada: ensaios sobre poesia, música e voz. Eds. Travassos, Elizabeth, Medeiros, Fernanda Teixeira de. Rio de Janeiro: Faperj; 7 Letras, 2008. p. 83-98. Impreso.

Obeso, Candelario. Cantos populares de mi tierra. Bogotá: Ministerio de cultura de Colombia. 2009. Impreso.

Ortiz, Javier, y Valdelamar, Lázaro. "La actividad intelectual de Candelario Obeso entre el reconocimiento y la exotización." Cuadernos de literatura del Caribe e Hispanoamérica 9 (2009): 9- 34. Web. 13 Nov. 2020.

Osorio, Nelson. "José María Arguedas y el lenguaje de la identidad mestiza." Revista América sin nombre 17 (2012): 75-80. Web. 18 Sep. 2020.

Ostria González, Mauricio. "Literatura oral, oralidad ficticia." Revista de Estudios filológicos 36 (2001): 71-80. Web. 26 Sep. 2020.

Palacios, Jorge. "El motivo de los bogas en la imaginación literaria de Jorge Isaacs y Candelario Obeso." Escritos. (2010): 156-184. Web.

Prescott, Lawrence. "'Negro nací: Authorship and Voice in Verses Attributed to Candelario Obeso." Afro- Hispanic review. (1993): 3-15. Web. 
Rama, Ángel. Prólogo. La novela-ópera de los pobres. Los Ríos profundos. Por José María Arguedas. Caracas: Fundacional Editorial el perro y la rana, 2006. 9-43. Impreso.

Rebaza, Luís. La construcción de un artista peruano contemporáneo. Lima: Pontificia Universidad Católica del Perú. 2000. Impreso. 